\title{
Mediating Role of Employee Decision on Relationship Between Employee Separation Planning and Retirement Preparedness in Kenya
}

\author{
Githaiga Gathiira ${ }^{1}$, Stephen Muathe ${ }^{2} \&$ James Kilika $^{2}$ \\ ${ }^{1}$ Department of Planning and Administration, Karatina University, Karatina, Kenya \\ ${ }^{2}$ Department of Business Administration, Kenyatta University, Nairobi, Kenya \\ Correspondence: Githaiga Gathiira, Department of Planning and Administration, Karatina University, P.O. Box, \\ 1954-10101, Karatina, Kenya.
}

Received: June 2, 2020

Accepted: July 10, 2020

Online Published: July 19, 2020

doi:10.5430/ijba.v11n4p82

URL: https://doi.org/10.5430/ijba.v11n4p82

\begin{abstract}
Globally, majority of employees particularly from public institutions are associated with poverty during retirement despite living well during employment life. Retirement preparedness is viewed as a deliberate planning process by an individual and ought to start a long while before actual organization - employee separation. It is therefore important to relook at the concept of employee separation planning and retirement preparedness when it is mediated by employee decision which is integral to the life mastery of control that an individual exhibit. The target population was 1,238 teachers aged 50 years and above and employed in public secondary schools in Kenya by 2017. A representative sample of 334 respondents was selected using multistage sampling technique. Data was collected using semi structured questionnaire and interview guide. Logit regression was used to establish the relationships between variables in the study and to test the null hypotheses at $\mathrm{P} \leq 0.05$ and $95 \%$ confidence level. The study found that employee decision making had partial mediating effect on the relationship between employee separation planning and retirement preparedness. The study recommended the government and the employer organizations to enact frameworks that encourages and stimulates employees to make decisions to engage in programmes geared towards separation planning for successful retirement preparedness.
\end{abstract}

Keywords: employee separation, separation planning, employee decision, retirement preparedness, mediating role, retirement planning

\section{Introduction}

Employee Separation planning (ESP) process is the starting point in retirement preparedness that individuals institute during employment life phase in anticipation of postretirement life (Shultz \& Wang 2011. Some researchers recommend that it ought to start long before individual exit employer organization (Gathiira, Muathe, Kilika, 2019b; Kutlu-Koc 2014). Demographic and labor force change patterns from various countries and regions such as United States, Western Europe, Japan, China, and India demonstrate that retirement preparedness is an area of global significance (Wang \& Shultz, 2011). There exist retirement dynamics that illuminate strategies for individual employees to maintain, negotiate or re-invent themselves during retirement (McVittie \& Goodall, 2012). Astoundingly, issues surrounding retirement planning are not taken seriously by employees and majority of older employees do not seriously start planning for retirement until they are very close to the actual retirement (Lusardi \& Mitchell, 2011; Wang \& Shultz, 2011). However, studies such as Moffatt and Heaven (2017) continue to demonstrate existence of positive association between retirement planning and retirement wellbeing which is an indicator of retirement preparedness. Earlier studies consistently indicate that approximately a third of retirees are vulnerable to poorer retirement adjustment and outcomes in terms of life satisfaction and quality of life since retirement wellbeing is dependent on available resources that include physical, cognitive, motivational, financial, social, and emotional resources (Tomczyk \& Klimczuk, 2019; Principi, Smeaton, Cahill, Barnes \& Socci, 2018). The retirees wellbeing is affected not only in financial resources but also in physical health and psychosocially. It is therefore imperative for employee to put in place programmes and activities to cater for the three areas (Potocnik \& Sonnentag, 2013; Thuku \& Ireri, 2013).

Conceptualizing retirement as decision making emphasizes retirement preparedness as a motivated choice behaviour and the characteristics of retirement transition process is embedded in the retirement decision (Feldman \& Beehr, 
2011; Taylor \& Earl, 2016). Majority of pre-retirees plan to work past mandatory retirement age either because of inadequate retirement income or due to improved health occasioning increased life expectancy. Moreover, working in retirement may be due to high engagement in work roles and deriving satisfaction from career jobs (Feldman \& Shultz, 2019), a characteristic of generation Y employees who pursue work that inspires passion and provides fulfilment to professional, personal and social goals (Deloitte, 2014). Researchers therefore argue that retirement process depend on employees planning decisions that generally focuses on the subjective life expectancy, a mental model concerning the years left before one dies (Hesketh, Griffin, Dawis \& Bayl-Smith, 2014; Maestas, 2010). The separation from employer organization to retirement is thus a transition with specific conduits determined by individual choices, implying retirement outcome is a rational decision that individuals must contend with (Adams \& Rau, 2011; Cahill, Giandrea \& Quinn, 2015). The foregoing justifies conceptualization of the decision making as mediating variable, included engagement in professional capital (learning), bridge employment and entrepreneurship activities. The study determined the role of employee decision as a mediator between employee separation planning and retirement preparedness.

\subsection{Statement of the Problem}

Employee retirement planning should not be a concern only during the second half of employee's life, but rather from start of employment (Gathiira et al., 2019b; Tomczyk \& Klimczuk, 2019). Workers with higher retirement self-efficacy tend to plan their retirement in advance (Valero \& Topa, 2014). Employee retirement planning becomes substantially more complex with considerations of broader aspects of the retirement preparation such as financial, physical and psychosocial adjustments (Hershey, Jacobs-Lawson \& Austin, 2012). In this study, employee separation planning was conceptualized to comprise programmes that covered financial, psychosocial and personal health planning aspects. Despite studies showing a positive relationship between retirement planning and retirement satisfaction, most employees including the older workers do not give separation from employer the planning it deserves (Moffatt \& Heaven, 2017; Wang \& Shultz, 2011). Some earlier studies indicate that individuals engage in clear predictive plans while others suggest that such plans tend to be less vivid (Ekerdt, Kosloski, \& De Viney, 2000; Winston \& Barnes, 2007). Feldman and Beehr (2011) posit that retirement decision-making is determined and driven by self-predictive future life as a retired individual, while sociological perspectives suggest that role of normative expectations and constraints direct choices and outcomes (Principi, et al., 2018). This makes the significance of individual judiciousness restrained (Weyman et al., 2012). This implies that the role of individual employee decisions in regard to retirement planning and retirement preparedness remain blurred. Past studies on retirement admit the significance of planning and posit the necessity for more research on the factors that might mediate or moderate any relationship between retirement planning and postretirement outcomes to improve support for individuals during this life transition (Wang \& Schultz, 2011). The purpose of the study was to assess the mediating role of employee decision on the relationship between employee separation planning and retirement preparedness, in Kenya a topic that is generally an explored. The study contributes to the existing scholarly antagonistic discourse of the retirement planning for retirement satisfaction, wellbeing and quality of life since knowledge gap persists.

\section{Literature}

\subsection{Theoretical Review}

From life course principle of "human agency within structure", individuals are presumed to have plans, make choices, and undertake actions within the opportunities and constraints of their social worlds, molded by personal history and social environments (Wang, Henkens \& Van Solinge, 2011). Role and continuity theories assume a continual progression in social roles without any disruptions, indicative of retirement plans remaining unaffected (Atchley, 1989; Quick \& Moen, 1998). However, life course perspective (LCP) recognizes the possibility of people making multiple entries and exits in work roles and thus retirement is not just an event but a process that affects individual's later life (Donaldson, Earl \& Muratore, 2010). Therefore, LCP was chosen to anchor employee separation planning programmes in preparation for retirement. The theory of planned behaviour (TPB) predicts people's deliberate behaviour whose central factor is individual's intentions as the motivational elements that influence behaviour performance (Ajzen, 1991). Therefore, from TPB, perceived behavioural control and behavioural intention can be used directly to predict behavioural achievement (Ajzen, 1985). The TPB has been used to explain a wide range of decisions and behaviours including entrepreneurial intentions (Kautonen, Van Gelderen \& Fink, 2013) and intentions to change careers (Khapova, Arthur, Wilderom \& Svensson, 2007). As such, the authors also employed TPB to anchor this study and assess the mediating effect of employee decision on the relationship between ESP and retirement preparedness. 


\subsection{Conceptual and Empirical Review}

Undoubtedly, studies exhibit existence of a positive association between retirement planning and retirement outcomes (Moffatt \& Heaven, 2017; Wang \& Schultz, 2011). Research has found various factors that significantly contribute to retirement outcomes, usually satisfaction, transition adjustment, and well-being (Principi, et al., 2018). The factors include psychological factors (Muratore \& Earl, 2015), retirement planning (Curl \& Ingram, 2013; Adams \& Rau, 2011), physical health (Moffatt \& Heaven, 2017), and financial factors (Thuku \& Ireri, (2013). The factors motivate the employee to deliberately initiate behavioral actions in preparation for separation from the employer organization (Gathiira, et al., 2019b). The employee separation planning was conceptualized to include programmes advertently undertaken by pre-retiree to envision financial, psychosocial and personal health planning aspects. Psychosocial planning programmes are non-work engagement activities such as volunteer work, community and religious groups which are significantly related to increased retirement well-being (Potocnik \& Sonnentag, 2013). Financial programmes such as investment, financial education and saving culture diversify income sources preparing the individual to meet the financial needs during retirement (Thuku \& Ireri, 2013). Similarly, the health of a retiree has great implications to individual employee's retirement preparedness (Feldman \& Shultz, 2019). The authors conceptualized employee separation planning to constitute psychosocial, financial and physical health programmes.

Employees perceive future selves in different environments such as bridge employment, full retirement and voluntary work with varying degrees of fit because individuals make diverse decisions during retirement transitions to enhance self-efficacy through application of adjustment behaviours Hesketh, et al. (2014). Longitudinal studies of post-retirement employment suggest that $30 \%$ to $50 \%$ of individuals' experience post-retirement employment (Maestas, 2010; Pleau, 2010; Warner, Hayward \& Hardy, 2010). In a similar view, Wang, Adam, Beehr and Shultz (2009) found that 50\% of the sampled retirees between 2002 and 2006 engaged in bridge employment at some point in time during the eight years that followed retirement. However, a longitudinal survey by Cahill, Giandrea and Quinn (2011) indicated a lesser proportion (15\%) of older North Americans who had a full-time professional career re-entering the workforce after retirement. In a study of antecedents and consequences of retirement planning and decision-making, bridge employment contributed to increased quality of life, satisfaction and adjustment to retirement by promoting social and psychological wellbeing of retiree (Topa, Moriano, Depolo, Alcover \& Morales, 2009). Part-time work is found to have a symbiotic relationship that contributes to the transfer of knowledge and experience to younger employees as well as prevent social exclusion in retirement (Van Dalen, Henkens, Henderikse \& Schippers, 2010; Zaniboni, Sarchielli \& Fraccaroli, 2010). As observed by Mariappanadar (2012) and Jenkins (2013), many pre-retirees are interested in participating in bridge employment to either meet financial obligations or social elements of retirement anxiety or both. It would be interesting therefore to investigate decisions made by pre-retirees and its role in retirement preparedness as they anticipate separation from the employer organization.

Studies have also shown that retirement would cease to be of interest as a separate and distinct period of time if people were able to pursue multiple careers over time in what Sargent, Lee, Martin and Zikic (2012) referred to as reinventing retirement. Through training and professional development, employees learn new skills and competencies and develop talents (professional capital) through lifelong learning (Pleau \& Shaumann, 2013). Furthering education affected individual's growth to new retirement pathways such as bridge employment since continued learning provided individual empowerment, hence more likely to enter re-employment than those without, an occurrence more probable to younger retirees (Pleau, et al., 2013). It can be theorized that younger retirees execute the strategies they had put in place during working life as they planned separation from the employer organization. As Barnett, van Sluijs and Ogilvie (2012) contend, the multiple environments available during retirement transition provide a rich stimulus to initiate new adjustment behaviors which affect the different retirement pursuits followed by an individual. This view is supported by the findings of Hesketh, et al. (2014) that, employees in transition to retirement should plan to creatively explore new opportunities that satisfy needs and provide outlets for skills and abilities in environments. Employee make decisions related to new social engagements, such as social entrepreneurship, volunteering, self-exploration, or other imagined possibilities (Sargent, et al., 2012; Zhao, Seibert \& Lumpkin, 2010). From the foregoing, the decisions made by an employee informed by knowledge accrued through analysis of the prevailing context undoubtedly silhouette the behaviour and outcome in retirement. The authors conceptualized decision making as a mediating variable that included engagement in professional capital (learning), bridge employment and entrepreneurship activities. This concurs with arguments of Wang and Shultz (2011) that, resources dynamically mediate the correlation between retirement and wellbeing, and between retirement planning and its realization. This study contributes to the evidence of association between employee separation planning and retirement preparedness when employee decision making is introduced as a mediator. The 
study assessed the mediating effect of employee decision making on the relationship between employee separation planning and retirement preparedness among pre-retiree secondary school teachers in the Kenyan context.

\subsection{Conceptualization and Hypothesis}

The association between employee separation planning components and retirement preparedness was proposed to have a linear relationship. Therefore, the components of ESP were explanatory variables and retirement preparedness the outcome variable. The authors further proposed that employee decision making mediated the relationship between ESP and retirement preparedness as shown in Figure 1.
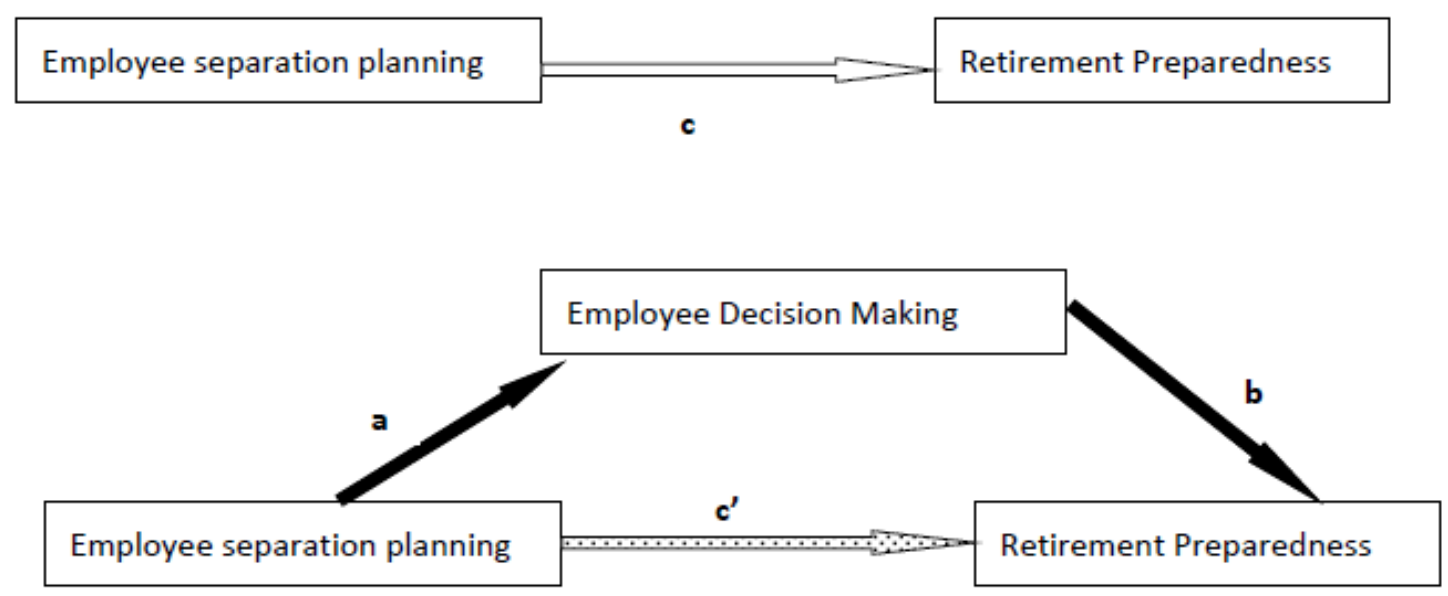

Figure 1. Diagram of a mediation model

Source: Lambert, et al (2012), adopted from Baron and Kenny (1986)

The model has been applied by Lambert, Negash, Stillman, Olmstead and Fincham (2012) to test commitment as a mediator of the relationship between phonography consumption and infidelity. From the empirical evidence exhibiting the necessity for more research on the factors that might mediate relationship between retirement planning and postretirement outcomes to improve support for individuals (Wang \& Schultz, 2011), and the theoretical literature; the authors proposed that the relationship between employee separation planning (explanatory variable) and retirement preparedness (outcome variable) was explained by their relationship to employee decision making (mediator). There being no other conflicting opinion in Kenya, the authors postulated that, employee decision making mediated the relationship between employee separation planning and retirement preparedness. The specific hypotheses were stated thus:

$\mathrm{H}_{1}$ There is a significant effect of employee separation planning and retirement preparedness among public secondary school teachers' in Kenya

$\mathrm{H}_{2}$ There is a significant effect of employee's decision making on the relationship between individual employee separation planning and retirement preparedness among public secondary school teachers' in Kenya

The hypotheses were based on the need to comprehend the influence of the decision making of pre-retirees in the context of planning for separation from employer organization and retirement preparedness. In other words, the study determined two issues. First, whether employee separation planning influenced retirement preparedness and secondly, whether employee decision making fell in the causal pathway between employee separation planning and retirement preparedness.

\section{Methodology}

\subsection{Context of the Study}

The Kenyan education system is categorized into basic, tertiary and higher education (MoE, 2010). Secondary schools are part of basic education, and their teachers are employed by the Teachers Service Commission (TSC) established under Article 237 of the Constitution of Kenya. The teachers have a mandatory retirement age (MRA) of 60 (TSC Circular No. 10/2014). Teacher management is devolved to County levels headed by County Directors of 
Education. The manager of the school is designated as Principal, and makes daily administrative decisions as the accounting officer supported by the Board of Management. The study focused on public secondary schools in Kirinyaga and Murang'a counties. The minimum qualification to teach in secondary school is Diploma in Secondary Education, level of education considered sufficient to inform the respondents the importance of planning for separation from the employer. The study was carried out in Kirinyaga and Murang'a Counties because the two had suffered great loss of life due to alcohol abuse compared to other Counties in Kenya (NACADA, 2014). In his earlier studies, Bamberger (2014), purported that, retirement as a significant life change may have a significant impact on older adults' drinking behavior, exacerbating prior patterns of heavy drinking or even precipitating in alcohol misuse.

\subsection{Design, Target Population and Sample Size}

This study employed descriptive research design since it provided a comprehensive and detailed explanation of the phenomena of pre-retiree teachers concerning employee separation planning and retirement preparedness, mediated by employee decision making (Chawla \& Sondhi, 2011). Study target population was 1,238 pre-retirees' secondary school teachers employed by the TSC in Kirinyaga and Murang'a Counties' and ten years to MRA by 2017. Most studies about retirement adjustment have not been conducted through a prospective approach but rather based on retrospective recall (Principi et al., 2016). The representative sample size was 334 (26.98\%) teachers. Multistage sampling technique was employed because the study population was scattered over a wide area (Chauvet, 2015). Identification of Kirinyaga and Murang'a Counties from the 47 Counties using convenience sampling formed stage one. Identification of school category (National, Extra County, County and Sub-County) through proportionate stratified sampling technique formed stage two. The last stage was selection of the actual respondents using purposeful sampling technique to identify TSC employed teachers aged 50 years and above.

\subsection{Research Data}

Semi-structured questionnaires were employed to collect the data which was triangulated by qualitative data collected by interview guide. The first section (A) had seven items on demographic characteristics of respondents. Section B had seventy items for employee separation planning as the composite explanatory variable. This was subdivided to three sections with sub variable psychosocial, financial and physical health programmes. The respondents expressed individual opinions on how well they participated in planning activities for separation from the employer upon retirement. The independent variable items had measurements in 5 - point Likert Scale namely; strongly disagree (1), disagree (2), uncertain (3), agree (4), and strongly agree (5). The third section, E contained the mediating variable (employee decision making). The items of measurement were also in 5 - point scale as follows; not at all (1), slight extent (2), moderate extent (3), high extent (4), and very high extent (5). To determine retirement preparedness, responses from respondents were also awarded scores using a 5 - point Likert Scale - definitely false (1), false (2), neither (3), true (4), and definitely true (5).

\subsection{Diagnostic Tests}

A variance inflation factors (VIF) of less than 10 and tolerance statistics of above 0.1 indicated there was no problem of multicollinearity (Field, 2013). Sampling adequacy for factor analysis was shown by values of Kaiser - Meyer Olkin (KMO) greater than 0.5 and confirmed by Bartlet's test of sphericity significant at $p=0.05$ (Field, 2013). Goodness of fit for the model, was indicated by Hosmer and Lemeshow (H-L) by $p>0.05$ (Chawla \& Sondhi, 2011).

\subsection{Data Analysis}

Descriptive statistics such as frequencies, percentages, means and standard deviation were employed to describe distribution and define significance of variables. Inferential statistics such as factor analysis, correlation and logit regression facilitated establishment of relationships between the study variables and to test the hypothesis (Field, 2013). Diagnostic tests included multicollinearity, sampling adequacy testing and goodness of fit of the model. Since the use of either Probit or Logit models provide efficient and consistent parameter estimates difficult to differentiate statistically (Field, 2013), the authors preferred logit model to test the statistical significance of the variables of the study. The statistical model is shown by equation 3.1 .

$$
\operatorname{Logit}[p]=\ln \left[\frac{p}{1-p}\right]=\beta_{0}+\beta_{1} X_{1}+\ldots+\beta_{n} X_{n}
$$

In determining mediation of employee decision on the relationship between ESP and the retirement preparedness the authors estimated models (3.2), (3.3) and (3.4) drawn to consider the four pathways (denoted as $\boldsymbol{a}, \boldsymbol{b}, \boldsymbol{c}, \boldsymbol{c}$ ' in figure 3.1) as recommended by Baron and Kenny (1986) cited by Field (2013). 


$$
\begin{gathered}
\text { Logit }[p]=\beta_{0}+\beta_{1} E S P+u_{i} \\
\text { EDM }=\beta_{0}+\beta_{1} E S P+u_{i} \\
\text { Logit }[p]=\beta_{0}+\beta_{1} E S P+\beta_{2} E D M+u_{i} \\
\text { Logit }[p]=\beta_{0}+\beta_{1} E D M+u_{i}
\end{gathered}
$$

Where:

Logit $[\mathrm{p}]$ is teachers' Retirement Preparedness,

ESP is Employee Separation Planning

EDM is Employee Decision Making

$\mathrm{B}_{0}$ is the Constant

$\beta_{1}$ and $\beta_{2}$ are the slope or parameters to be estimated

$\mathrm{u}_{\mathrm{i}}$ is the error term or random variables

Model (3.2) is a regression predicting retirement preparedness from the predictor variable (ESP), a composite variable made of psychosocial, financial and personal health programmes, path denoted $\boldsymbol{c}$. Model (3.3) is a regression predicting the mediator (employee decision making) from ESP variables, path denoted $\boldsymbol{a}$. Model (3.4) is a regression predicting retirement preparedness from both ESP and the employee decision making through the path denoted as $c^{\text {' }}$ and simultaneously estimate Model 3.5 by predicting the retirement preparedness through the path denoted as $\boldsymbol{b}$ in figure 3.1. According to Baron and Kenny (1981) cited by Field (2013), these four (4) models test the four conditions of mediation: first, the predictor variable must significantly predict the outcome variable in model (3.2). Second, the predictor variable must significantly predict the mediator in model (3.3). Third, the mediator must significantly predict the outcome variable in model (3.5) and fourth, the predictor variable must predict the outcome variable less strongly in model (3.4) than in model (3.2). However, the study employed the Hayes's PROCESS tool that allowed a "forced entry" of the variables for models (3.2) and (3.3) stepwise (Field, 2013). The Hayes's PROCESS tool exhibit presence of mediation if Sobel test presents a P value of equal to or less than $0.05(p \leq 0.05)$.

Employee separation planning for retirement preparedness by pre-retirees was assessed through respondents' engagement in psychosocial, financial and personal health programmes. To measure psychosocial programmes, 24 items were formulated to seek responses in social embeddedness, mentorship opportunities and retirement counselling. Similarly, to measure financial programmes, 24 items were formulated to seek responses in asset investment, financial education and saving culture. Finally, to measure personal health programmes, 20 items were formulated to seek responses in eating healthy, accessing health education, avoiding substance abuse, physical exercise and health care plans. The items were in a 5 - point Likert scale that ranged from strongly disagree (1), disagree (2), uncertain (3), agree (4) to strongly agree (5). Employment decision making had 13 items to measure learning/professional capital, bridging employment and engagement in entrepreneurship.

\section{Research Findings}

\subsection{Variables Characteristics}

The three explanatory variables (Psychosocial Programmes, Financial Programmes, Personal Health Programmes) that made the composite (employee separation planning) and the mediator (employee decision making) were used for the respondents to express their opinions on extent of engagement. The characteristics of the variables were as shown in Table 1. 
Table 1. Variable characteristics

\begin{tabular}{lllll}
\hline Variables & No. of Items & Cronbach's Alpha & Mean & S.Dev. \\
\hline Psychosocial Programmes & 24 & 0.819 & 3.047 & 1.107 \\
\hline Financial Programmes & 24 & 0.865 & 2.869 & 1.235 \\
\hline Personal Health Programmes & 20 & 0.734 & 2.713 & 1.145 \\
\hline Employee separation planning & 69 & 0.902 & 2.881 & 1.159 \\
\hline Employee's Decision Making & 13 & 0.761 & 2.431 & 1.290 \\
\hline Retirement Preparedness & 10 & 0.809 & 3.075 & 1.211 \\
\hline
\end{tabular}

Source (Survey data, 2017)

Cronbach's alpha values indicate different measures of reliability. Between 0.5 and 0.6 is fair reliability, 0.6 and 0.7 satisfactory, 0.7 and 0.8 as good and 0.8 to 1.0 as very good reliability (Field, 2013; Zikmund, Babin, Carr \& Griffin, 2010). The authors considered Cronbach's alpha value of $\geq 0.7$ as the threshold of good reliability. As shown by Table 1, employee separation planning items had very good reliability (0.902) with a mean score of 2.881 and standard deviation of 1.159. Similarly, items of the constituent variables had acceptable reliability since it was above 7. The mediating variable items also exhibited good reliability of more than 7 , hence acceptable.

\subsection{Summary of Aggregate Mean Scores for the Variables}

In order to illustrate the emerging scenario among the study variables measured, the variables aggregate mean score and corresponding standard deviations were summarized as presented in Table 2.

Table 2. Summary of aggregate mean scores

\begin{tabular}{lll}
\hline Variable & Aggregate Mean & Standard Deviation \\
\hline Employee separation planning & $\mathbf{2 . 8 7 7}$ & $\mathbf{1 . 1 7}$ \\
\hline Psychosocial Programmes & 3.05 & 1.12 \\
\hline Financial Programmes & 2.87 & 1.24 \\
\hline Personal Health Programmes & 2.71 & 1.15 \\
\hline Employment Decision Making & $\mathbf{2 . 4 3}$ & $\mathbf{1 . 2 9}$ \\
\hline Learning/professional capital & 2.28 & 1.29 \\
\hline Bridging employment & 2.46 & 1.32 \\
\hline Engagement in entrepreneurship & 2.60 & 1.26 \\
\hline Retirement Preparedness & $\mathbf{3 . 0 8}$ & $\mathbf{1 . 2 1}$ \\
\hline Psychosocial wellbeing & 3.51 & 1.17 \\
\hline Financial wellbeing & 2.57 & 1.19 \\
\hline Physical wellbeing & 3.00 & 1.28 \\
\hline
\end{tabular}

Source (Survey data, 2017)

Employee separation planning had an aggregate mean score of 2.88 and a standard deviation of 1.17. This mean score being at the level of indifferent (when rounded off), denoted that the level of employee separation planning by pre-retiree teachers was in doubt. Pre-retirees' engagement in psychosocial programmes had an aggregate mean score of 3.05 and a standard deviation of 1.12 which suggested that pre-retiree teachers' participation in activities that foster mentorship opportunities, social orientation, and retirement counseling was indistinguishable. The findings concur with Gathiira et al. (2019b) and Itika (2011) that, despite mentorship, coaching, community involvement and volunteer activities being essential in employee retirement planning, employees seldom participate as expected. Considering the empirical findings that psychosocial factors such as social embeddedness, are essential 
in retirement planning (Shultz \& Henkens, 2010), the study findings raises a great concern on retirement preparedness. Pre-retirees' engagement in financial programmes had aggregate mean score of 2.87 and a standard deviation of 1.24 suggesting that pre-retiree teacher's involvement in asset investment, financial education and a culture of saving were deficient. This study leaned towards findings of RBA (2012) that 13\% of retirees' investments in businesses failed to survive while those that survived provided income that was inadequate to meet life needs. The findings exposed deficiency in accessing financial education that provides empowerment in financial management (Gathiira, Muathe \& Kilika, 2018). The finding concurs with past studies and theoretical arguments that prospective retirees from the public sectors had poor access to retirement education and have inadequate levels of financial literacy (Thuku \& Ireri, 2013; Wang \& Hesketh, 2012; Ntalianis \& Wise, 2011). This elucidates the theoretical arguments of Hesketh and Griffin (2010) that employees with weak financial knowledge fail to perform even the most basic planning activities when confronted by complexities of the modern world investing options.

The aggregate mean score for employee engagement in personal health programmes was 2.71 and a standard deviation of 1.15 , portraying uncertainties in retirement planning related to health. However, the study findings indicated that the respondents valued eating healthy $(\mathrm{M}=3.16$; $\mathrm{SD}=1.18)$. The study findings agreed with past researchers that health diet is perceived important in maintaining physical wellbeing in retirement (Gathiira, Muathe \& Kilika, 2019a; Wang \& Hesketh, 2012). Regrettably, despite pre-retirees valuing eating healthy, financial resources to provide balanced diet were scarce since $29.1 \%$ (88) admitted having the desire to eat a balanced diet but struggling to afford. The pre-retiree made effort to access health education $(\mathrm{M}=3.52 ; \mathrm{SD}=1.16)$ through listening to media programmes $(\mathrm{M}=4.08 ; \mathrm{SD}=1.04)$ and reading literature $(\mathrm{M}=3.71 ; \mathrm{SD}=1.16)$. In theory, the findings agree with life course perspective that retirement transitions are embedded to broader life trajectories that include personal health of the employee (Vickerstaff et al., 2008). Health care plans undertaken by the respondents had a mean score of 2.79 and standard deviation of 1.24 suggesting pre-retiree level of engagement in health care plans was dire. Health care plans are key because working during retirement is dependent on individuals' health status (Wang, Olson \& Shultz, 2013).

The pre-retirees' decision making mean score of 2.43 and a standard deviation of 1.29 suggested individuals engaged in the activities to a slight extent. From Table 2, all the sub variables measuring employee decision making had mean scores that indicated pre-retirees' slight extent; learning to build professional capital $(\mathrm{M}=2.28 ; \mathrm{SD}=1.29)$, bridging employment $(\mathrm{M}=2.46 ; \mathrm{SD}=1.32)$ and engagement in entrepreneurship $(\mathrm{M}=2.60 ; \mathrm{SD}=1.26)$. However, the relatively large standard deviation suggests existence of dispersed responses. Respondents reported to have acquired sufficient competences to a moderate extent as adequate empowerment to work in retirement $(\mathrm{M}=2.79 ; \mathrm{SD}=1.36)$. Three quarters exhibited a small extent and not at all when asked about engagement in further studies to facilitate involvement in part time employment during retirement $(\mathrm{M}=2.02$; $\mathrm{SD}=1.18)$. The findings were contrary to Pleau and Shaumann (2013) that, further education affects individual's growth of new retirement pathways such as bridge employment. The respondents to a moderate extent had plans to continue working in retirement $(\mathrm{M}=.06 ; \mathrm{SD}=1.47)$ in a different career field $(\mathrm{M}=.98 ; \mathrm{SD}=1.41)$ and same career field employment $(\mathrm{M}=1.70 ; \mathrm{SD}=1.07)$. The respondents vehemently denied the probability of missing teaching during retirement $(\mathrm{M}=2.11 ; \mathrm{SD}=1.31)$. However, the relatively large standard deviations imply that the responses were in a continuum. The study findings suggest retirees' possibility of career change employment as a preferred type of bridge employment during retirement. The study concurs with the theoretical arguments that bridge employment can be perceived as a role transition from full time work as well as an opportunity to maintain social relationships and life style patterns in accordance to role theory and continuity theories respectively (Mariappanadar, 2012). Studies have found that some employees extend working life through bridge employment as continued career or in a type of hybrid employment while very few employees decide on traditional full leisure retirement (Wang et al., 2009; Shultz \& Henkens, 2010).

In assessing pre-retirees' engagement in entrepreneurship activities the item that got the highest mean score $(M=3.45$; $\mathrm{SD}=1.20$ ) was investments to supplement salary. Some pre-retirees planned to start a business after retirement $(\mathrm{M}=3.10 ; \mathrm{SD}=1.42)$ while more than half of the respondents denied not having intentions to start a business in retirement (M=1.87; $\mathrm{SD}=1.28)$. The findings tend to agree with Adams and Rau (2011) opinions that retirement planning and preparation is a rational decision that individuals are expected to contend with. A probable explanation may be due to the challenges of monitoring the entrepreneurial activities due to the requirement of teachers spending most of their time including weekends in school. The findings further concur with Van Dalen, et al (2010) findings that older workers' retirement processes are an outcome of individual decision making processes within the context of the opportunities and constraints provided by employer organization. On the contrary, this may be because retirement preparation kicks off with planning and decision making usually far before the actual end of one's working life (Feldman \& Beehr, 2011). The overall aggregate mean score for retirement preparedness (outcome 
variable) was 3.08 and standard deviation of 1.21. This indicated uncertainty among the respondents on the level of retirement preparedness. The findings of this section make a vital contribution to retirement preparedness since the outcome of sound retirement preparation is integral to fiscal, physical and psychological wellbeing (Wang \& Hesketh, 2012). In any case, individuals prepared for retirement suffer less anxiety concerning retirement (Valero \& Topa, 2014).

\subsection{Test of Hypothesis}

The collinearity tests conducted using correlation analysis, indicated that there was no problem of multicollinearity because all the variables had tolerance statistics far above 0.1 (lowest 0.659 ) and VIF analysis was far below 10, the highest being 1.422 (Field, 2013). The principal component analysis with varimax rotation indicate that data sample of this study was adequate for factor analysis because $\mathrm{KMO}$ was 0.800 (greater than 0.5 ), Bartlett's test of sphericity being significant, $\mathrm{P}=0.000,(\mathrm{p} \leq 0.05$ ). The model also passed the goodness of fit test since Hosmer and Lemeshow $(\mathrm{H}-\mathrm{L})$ test had a chi square 7.029 and $\mathrm{P}$ value of $0.534(\mathrm{P}>0.05)$. In testing the first hypothesis, that there is a significant effect of employee separation planning and retirement preparedness among public secondary school teachers' in Kenya, the authors considered logic model (3.2) as well as that of constituent variables as shown in Table 3.

Table 3. Employee separation planning and retirement preparedness

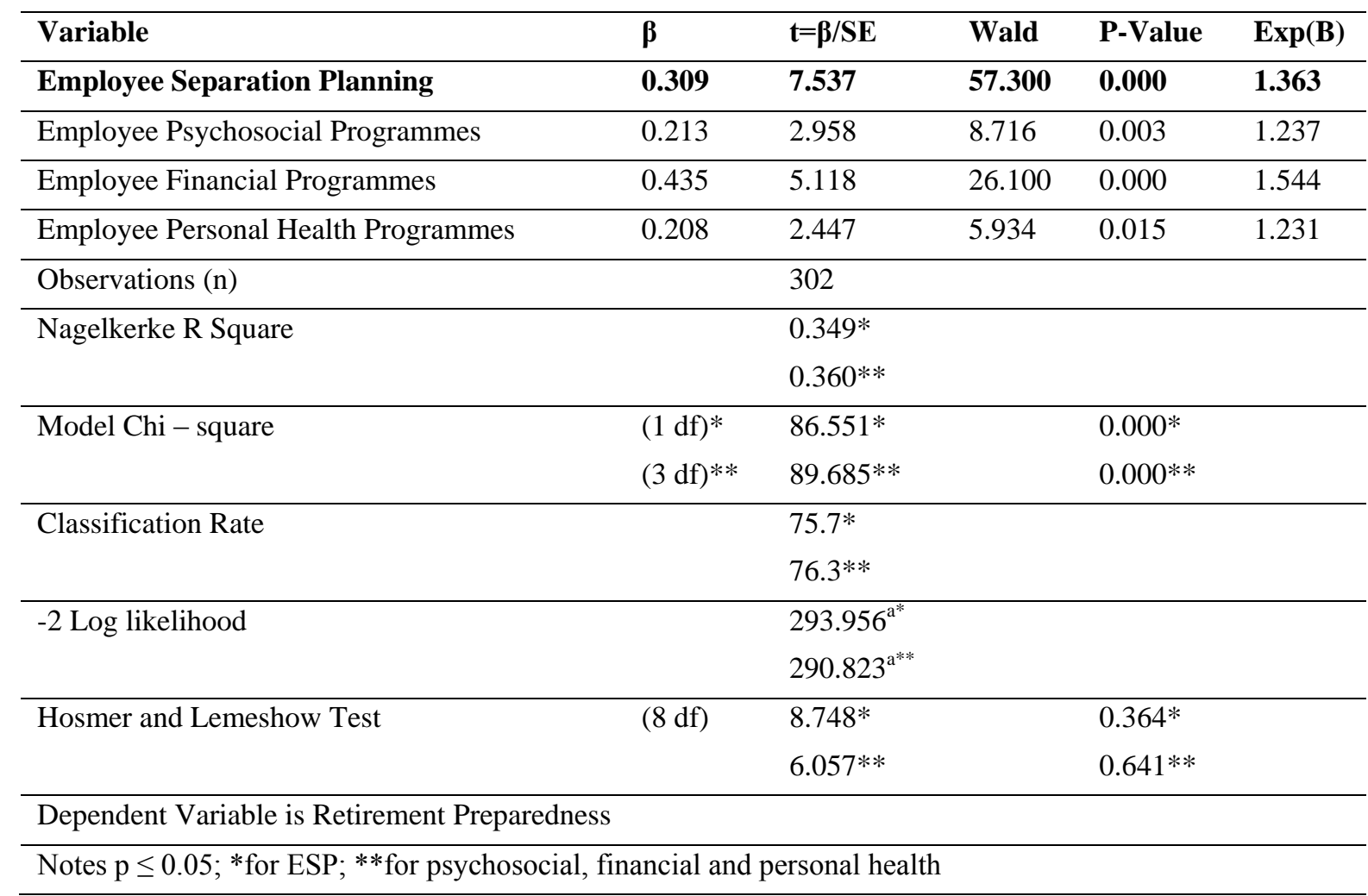

Source (Survey data, 2017)

The likelihood ratio, chi square of 86.551 and 89.685 at $\mathrm{P}$ - value of 0.000 indicates that the model was significantly sound. The Nagelkerke R Square of 0.349 implied that the model variables explained $34.9 \%$ of the variation in the retirement preparedness (outcome) which is a significant relationship. The -2 Log likelihood was 293.956 indicated that the model fitted the research data. The prediction sensitivity had an overall success rate of $75.7 \%$. The Hosmer and Lemeshow test yielded a chi square of 8.748 with 8 degrees of freedom (df) and a $\mathrm{P}$ - value of 0.364 which was non-significant, indicating that the data fitted the model well. The log of the odds of pre-retiree retirement preparedness was found to be positively related to predictor variables (composite and constituent's variables) due to the positive sign of the $\beta$ value and were all statistically significant with P- values less than 0.05 . However, financial programmes had the greatest effect on retirement preparedness, followed by psychosocial programmes. Thus, from 
the statistical test conducted, the first hypothesis was supported and the study accepted $\mathrm{H} 1$ that, there is a significant effect of employee separation planning and retirement preparedness among public secondary school teachers' in Kenya since $\beta \neq 0$ and $p$ - value was significant $(P=0.000)$, that is less than 0.05 . The study therefore concluded that there is a significant positive relationship between employee separation planning and retirement preparedness in pre-retiree teachers of public secondary schools in Kenya.

In testing the second hypothesis that there is a significant effect of employee's decision making on the relationship between individual employee separation planning and retirement preparedness among public secondary school teachers' in Kenya, the study determined whether employee decision making falls in the causal pathway between ESP and retirement preparedness. The study anticipated that the types of activities pursued by individual pre-retiree teachers molded the components to operationalize the ESP. Employing the Lambert's mediation model by means of the Hayes's PROCESS tool, a "forced entry" of the variables was conducted for models (3.3) and (3.4) stepwise and results were as shown in Table 4.

Table 4. Logistic regression for mediation relationship

\begin{tabular}{|c|c|c|c|c|}
\hline Variable & $\boldsymbol{\beta}$ & SE & $\mathbf{Z}$ & P-Value \\
\hline \multicolumn{5}{|l|}{ Employee Decision Making (Outcome) } \\
\hline Employee Separation Planning(ESP) & 0.0948 & 0.0168 & 5.6480 & 0.000 \\
\hline $\mathrm{R}^{2}$ value & & 0.0970 & & 0.000 \\
\hline \multicolumn{5}{|l|}{ Retirement Preparedness (Outcome) } \\
\hline Employee Decision Making (EDM) (indirect effect) & 0.2482 & 0.1120 & 2.2155 & 0.0267 \\
\hline Employee Separation Planning (ESP) (Direct effect) & 0.2941 & 0.0414 & 7.0990 & 0.000 \\
\hline Nagelkerke R Squared & & 0.3646 & & 0.000 \\
\hline Model LL & & 90.9326 & & \\
\hline -2 Log likelihood & & -288.7720 & & \\
\hline $\begin{array}{lllll}\begin{array}{l}\text { Employee } \\
\text { effect) }\end{array} & \text { Separation } & \text { Planning } & \text { (ESP) } & \text { (Indirect } \\
\end{array}$ & 0.0235 & 0.0129 & & \\
\hline BootLLCI & & 0.0035 & & \\
\hline BootULCI & & 0.0545 & & \\
\hline Sobel test & 0.0235 & 0.0116 & 2.0350 & 0.0418 \\
\hline Observations (n) & & 299 & & \\
\hline
\end{tabular}

Source (Survey data, 2017)

The regression analysis of employee decision making (EDM) predicted by employee separation planning (ESP), model 3.3 through path $a$ revealed that, ESP significantly predicts relationship EDM $(\beta=0.0948, \mathrm{z}=5.648, \mathrm{p}$ $=0.0000)$. The $\mathrm{R}^{2}$ value indicated that ESP explains $9.7 \%$ of the positive relationship with EDM since $\beta$ was positive. This connotes that, as ESP activities increased employee decision making increased and vice versa. It is noticeable that ESP significantly predicted retirement preparedness in a positive relationship even with relationship EDM in the model 3.4 through path $c^{\prime},(\beta=0.2941, \mathrm{z}=7.099, \mathrm{p}=0.0000)$. Similarly, relationship EDM, Model 3.5 through path $b$ also significantly predicted retirement preparedness in a positive relationship $(\beta=0.2482, \mathrm{z}=2.2155, \mathrm{p} 0.0267)$. The positive $\beta$ values in the two relationships inform that as each of ESP and EDM activities increased, retirement preparedness increased as well. It was also noteworthy that Nagelkerke $\mathrm{R}^{2}$ value indicated that the model explained $36.46 \%$ of the variance in retirement preparedness. Further analysis revealed that the indirect effect of ESP on retirement preparedness, Model 3.4 through paths $a$ and $b$ gave $\beta=0.235$, BootLLCI $=0.0035$, BootULCI $=0.0545$. This range of confidence interval between 0.0035 and 0.0545 does not include zero that is, $\beta \neq 0$, implying that EDM has a small but meaningful mediating effect in the relationship between employee separation planning and retirement preparedness. The Sobel test for the normal theory test for the indirect effect also revealed a significant indirect 
relationship between ESP and retirement preparedness, $\beta=0.0235, z=2.035, p=0.0418$. These findings point that EDM is a mediator of the relationship between employee separation planning and retirement preparedness. The mediation model analysis is presented in Figure 4.2.

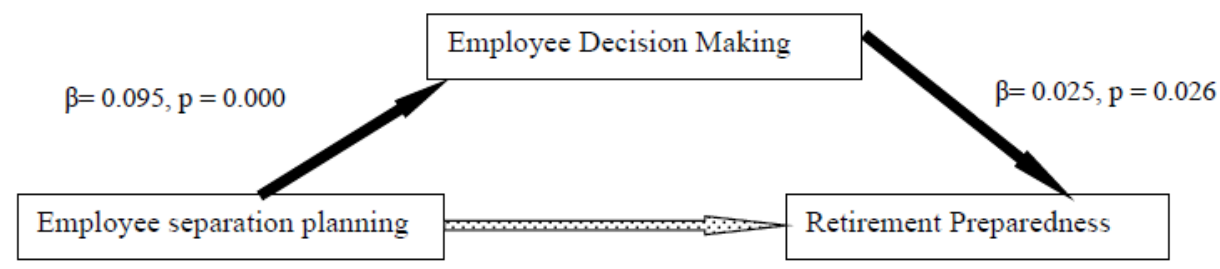

Direct effect, $\beta=0.029, p=0.000$

Indirect effect, $\beta=0.235,95 \% \mathrm{CI}[0.004,0.042]$

Figure 2. Mediation conceptual model

Since the $\mathrm{P}$ value of the Sobel test for the indirect effect was significant $(\mathrm{P}=0.0418)$ mediation was present. However, since ESP remained significant $(\mathrm{P}=0.000)$ even after controlling EDM, the mediation was partial. From the statistical analysis results the authors proposed that the relationship between ESP and retirement preparedness was mediated by EDM. Therefore, the study hypothesis was supported and the authors accepted the $\mathrm{H}_{2}$ that there is a significant effect of employee's decision making on the relationship between individual employee separation planning and retirement preparedness among public secondary school teachers' in Kenya.

\section{Discussions and Implications}

From recommendations of more research on the factors that might mediate or moderate any association between retirement planning and wellbeing, satisfaction and adjustments outcomes in retirement, the study assessed the mediating role of employee decision on the relationship between employee separation planning and retirement preparedness. The study indicated that life course perspective and the theory of planned behaviour presents some appropriate theoretical underpinnings in the study of retirement trajectories considered in this study (Kautonen, Van Gelderen \& Fink, 2013; Donaldson, Earl, \& Muratore, 2010). Employee separation planning was conceptualized to constitute pre-retirees' engagement in psychosocial, financial and personal health programmes while employee decision making was intellectualized to comprise learning/professional capital, bridge employment and entrepreneurship. Employee separation planning had an aggregate mean score of 2.88 and a standard deviation of 1.17. The mean score signified that the level of employee separation planning by pre-retiree teachers was uncertain. In presenting a similar, psychosocial, financial and personal health programmes measures also exhibited mean score of less than 3 implying pre-retirees were indeterminate of extent of participation in activities related to separation planning. Despite the findings of other studies that psychosocial factors such as social embeddedness, are essential in retirement planning (Gathiira et al., 2019b; Shultz \& Wang, 2011), the study findings paint a blurred image of retirement preparedness by pre-retiree teachers. In support of previous studies (Gathiira, Muathe \& Kilika, 2018), the study portrayed that pre-retirees had not engaged in activities that provided financial literacy and investment to supplement salary income to an extent of majority not meeting recurrent expenditure in the absence of salary. This is notwithstanding theoretical arguments that prospective retirees from the public sectors had poor access to retirement education and have inadequate levels of financial literacy (Thuku \& Ireri, 2013; Wang \& Hesketh, 2012; Ntalianis \& Wise, 2011). Pre-retirees exhibited valuing eating healthy but financial resources to provide balanced diet were scarce, made effort to access health education through listening to media programmes and reading literature. In theory, the findings agree with life course perspective that retirement transitions are embedded to broader life trajectories that include personal health of the employee (Vickerstaff et al., 2008; Wang, et.al., 2013) because retirement outcome is dependent on individuals' health status.

The pre-retirees' decision making aggregate mean score of 2.43 and a standard deviation of 1.29 suggested individuals engaged in the activities to a slight extent, an observation that was made in all the sub-variables (learning to build professional capital $\mathrm{M}=2.28$; $\mathrm{SD}=1.29$, bridging employment $\mathrm{M}=2.46 ; \mathrm{SD}=1.32$ and engagement in entrepreneurship $\mathrm{M}=2.60 ; \mathrm{SD}=1.26$ ). Contrary to Pleau and Shaumann (2013) that further education affects 
individual's growth of new retirement pathways pre-retirees' engagement in further studies was to a small extent. However, respondents preferred continuing working in a different career field during retirement as opposed to same career field employment. Therefore, the study findings suggest retirees' possibility of career change employment as a preferred type of bridge employment during retirement. This finding give emphasis to the theoretical arguments that bridge employment can be perceived as a role transition during retirement transition as well as an opportunity to maintain social relationships and life style patterns in accordance to role theory and continuity theories respectively (Mariappanadar, 2012; Shultz \& Henkens, 2010; Wang et al., 2009). Engagement in entrepreneurship activities had investments as the item with highest mean score $(\mathrm{M}=3.45 ; \mathrm{SD}=1.20)$ with some pre-retirees having intentions to start a business after retirement. This may be due to challenges of monitoring entrepreneurial activities in the light of teachers spending most of their time including weekends in school. The findings tend to concur with past studies that retirement outcome are integral to individual decision making processes within the context of existing opportunities and constraints, and that retirement planning and preparation is a rational decision that individuals are expected to contend with (Adams \& Rau, 2011; Van Dalen, et al., 2010). This may be because retirement preparation commences with planning and decision making usually far before the actual end of one's working life (Feldman \& Beehr, 2011). As such, empowering programmes related to psychosocial, financial and personal health programmes are imperative in facilitating employee separation planning.

The study results from hypotheses testing were as anticipated, by showing positive relationship between employee separation planning and retirement preparedness, as well as exhibiting a mediating effect of employee decision making on the said relationship (Principi, et al., 2018). The study concluded that employee decision making had a significant partial mediating effect on the relationship between employee separation planning and retirement preparedness. Studies indicate that retirees who engage in bridge employment have fewer major diseases and functional limitations compared to retirees who choose full rest retirement since level of physical and/or cognitive activities assist in maintaining individual's physical health (Wang \& Shultz, 2011; Zhan, Wang, Liu \& Shultz, 2009; Griffin \& Hesketh, 2008). Research studies reveals that choice(s) is among the numerous options that include paid and unpaid bridge employment, pursuit of entrepreneurial activities, second careers and lifelong learning (Von Bonsdorff, Shultz, Leskinen \& Tansky, 2009; Wang \& Shultz, 2011). Similarly, Gray, H. (2007) posit that retirees with higher entrepreneurial orientations are more likely to engage in career bridge employment than full retirement. Learning processes were particularly important during retirement transition as they shape evolving needs, values and associated expectations for reinforcers in the environments such as attending a retirement transition seminar (Hesketh, Griffin, Dawis, \& Bayl-Smith, 2014). This is because, the individual's adaptability during late career and retirement transition is central to one's empowerment to enable switch from full-time work to bridge employment (Hesketh et al., 2014). Remarkably, the move from full-time to part-time employment, paid to voluntary work or to no work is a proactive mode of adjustment to the changing environment steered by individual's decisions.

The study reinforces the application of life course perspective and the theory of planned behaviour that deliberate individual decisions and behaviours like entrepreneurial intentions, continuous learning, career change intensions, and workplace environment practices are integral in separation planning. Taking this argument further, the intention of individuals making deliberate choices is to have perceived behavioural control guided by self-efficacy beliefs that influence the choice of activities. In this respect, employees are said to make decisions to ensure continuity of postretirement work activities (staying active) and social life (contact to others) that was perceived important to the individuals before retirement (Deller, Liedtke, \& Maxin, 2009). This buttresses theoretical arguments behind role theory, continuity theory and life course perspective. The study findings therefore provide empirical evidence of more factors that reinforces the theoretical underpinnings as well as mediate employee separation planning and retirement preparedness, indicated by positive retirement outcomes (wellbeing, satisfaction and adjustment). The theoretical underpinnings of the study demonstrated that retirees that engaged in bridge employment had fewer major diseases and functional limitations compared to full rest retirement since level of physical and/or cognitive activities assist in maintaining individual's physical health (Wang \& Shultz, 2010; Zhan, et al., 2009). The study concurred with past studies that bridge employment, (surprisingly with preference to a different career field (second careers)), pursuit of entrepreneurial activities and lifelong learning were pertinent decisions to consider among other numerous options in planning for separation from employer organization (Von Bonsdorff, Shultz, Leskinen \& Tansky, 2009; Wang \& Shultz, 2010).

\section{Conclusions and Policy Implications}

The study was on determining the mediating role of employee decision making on the relationship between employee separation planning and retirement preparedness in Kenya. The study found that employee decision making had small but meaningful mediating effect in the relationship between employee separation planning and 
retirement preparedness. The study reinforced the underpinnings life perspective theory and theory of planned behaviour in anchoring retirement planning and retirement preparedness research. The study found that, Individuals make plans, choices, and take actions shaped by personal history and social circumstances in order to mould future outcomes. Pre-retirees deliberately make decisions that accommodate continuity in the retirement life where roles are different from those of employer organization cautious that little or no disruptions occur. The study therefore concluded that employee decision making had a significant partial mediating effect to employee separation planning and retirement preparedness in ensuring psychological, social, financial and physical wellbeing. The separation programmes are broadly related to psychosocial, financial and personal health. The decisions to be made by individual employee include continuous learning or professional capital; bridge employment and entrepreneurship endeavours.

The implication of this finding is that, it is imperative for the employees to have mastery of clear and specific goals beyond working life so as to have perceived behavioural control. Retirement planning programmes in preparation to the anticipated separation from employer organization in terms of psychosocial, financial or personal health activities depend on the rational decisions made by the individual, with the study showing financial programmes to be more important. The study extends the body of knowledge in the last process of human resource management (retirement or separation) by supporting the proponents of life course perspective and the theory of planned behaviour that individuals make adaptive choices over time to preserve and maintain existing internal and external structures. In so doing, individuals do not cleave to the past but adjust and adapt to unfolding circumstances that ensures considerable continuity in identity and self-concept over the retirement transition guiding the individual behaviour as dictated by social structure. The individual employees make deliberate choices to have perceived behavioural control guided by self-efficacy beliefs that influence the choice of activities. In practice, the human resource managers in employer organization should devise mechanisms of building capacity to facilitate employees make the right decisions in view of employee separation planning for wellbeing in post-employment life. Moreover, in its endeavour to meet Vision 2030 blue print, the government of Kenya should put in place a national strategy and partner with other institutions to promote and support employees in making decisions towards separation planning in preparation for retirement. This would be an enabler of senior citizens to age gracefully and independently.

\section{Recommendations for Further Research}

The study was conducted in only two Counties and the respondents were from the educational sector only (public secondary school teachers). In addition, the study employed cross-sectional design. Future studies could therefore be extended to other industries such as banking, manufacturing, technological, construction among others in order to enrich the knowledge of separation planning and retirement preparedness.

\section{References}

Adams, G. A., \& Rau, B. L. (2011). Putting Off Tomorrow to Do What You Want Today. American Psychologist, 66(3), 180-192. https://doi.org/10.1037/a0022131

Ajzen, I. (1985). From intentions to actions: A theory of planned behaviour. In J. Kuhi, \& J. Beckmann (Eds.), Action control: From cognition to behaviour (pp. 11-39). Heidelberg: Springer. https://doi.org/10.1007/978-3-642-69746-3_2

Ajzen, I. (1991). Organizational Behaviour and Human Decision Processes. University of Massachusetts, 50, 179-211. https://doi.org/10.1016/0749-5978(91)90020-T

Atchley, R. C. (1989). A continuity theory of normal aging. Gerontologist, 29, 183-190. https://doi.org/10.1093/geront/29.2.183

Bamberger, P. A. (2014). Winding Down and Boozing Up: The Complex Link Between Retirement and Alcohol Misuse. Work, Aging and Retirement, 1-20. https://doi.org/10.1093/acprof:oso/9780199374120.003.0001

Barnett, I., Van Sluijs, E. M., \& Ogilvie, D. (2012). Physical activity and transitioning to retirement: A systematic review. American Journal of Preventive Medicine, 43, 329-336. https://doi.org/10.1016/j.amepre.2012.05.026

Cahill, K. E., Giandrea, M. D., \& Quinn, J. F. (2015). Retirement patterns and the macroeconomy, 1992-2010: The prevalence and determinants of bridge jobs, phased retirement, and re-entry among three recent cohorts of older Americans. The Gerontologist, 55, 384-403. https://doi.org/10.1093/geront/gnt146

Cahill, K., Giandrea, M., \& Quinn, J. (2011, June). Reentering the labor force after retirement. Monthly Labor Review, 34-42. 
Chauvet, G. (2015). Coupling Methods for Multistage Sampling. The Annals of Statistics, 43(6), 2484-2506. https://doi.org/10.1214/15-AOS1348

Chawla, D., \& Sondhi, N. (2011). Research Methodology: Concepts and Cases. New Delhi: Vikas Publishing House Pvt Ltd.

Curl, A. L., \& Ingram, J. G. (2013). Anticipatory socialization for retirement: A multilevel dyadic model. Clinical Gerontologist, 36, 375-393. https://doi.org/10.1080/07317115.2013.788117

Deller, J., Liedtke, P. M., \& Maxin, L. (2009). Old-age security and silver workers: An empirical survey identifies challenges for companies, insurers and society. Geneva Papers on Risk and Insurance - Issues and Practice, 34, 137-157. https://doi.org/10.1057/gpp.2008.44

Deloitte. (2014). Big demands and high expectations, the Deloitte Millennial survey. Retrieved from http://www2.deloitte.com/content/dam/Deloitte/global/Documents/About-Deloitte/gx-dttl-2014-millennial-surv ey-report.pdf

Donaldson, T., Earl, J. K., \& Muratore, A. M. (2010). Extending the integrated model of retirement adjustment: Incorporating mastery and retirement planning retrieval. Journal of Vocational Behaviour, 77, 279-289. https://doi.org/10.1016/j.jvb.2010.03.003

Ekerdt, D. J., Kosloski, K., \& De Viney, S. (2000). The normative anticipation of retirement by older workers. Research on Aging, 22, 3-22. https://doi.org/10.1177/0164027500221001

Feldman, D. C., \& Beehr, T. A. (2011). A three-phase model of retirement decision making. American Psychologist, 66, 193-203. https://doi.org/10.1037/a0022153

Feldman, D. J., \& Shultz, K. S. (2019). Career embeddedness and career crafting among older workers. In K. S. Shultz, \& G. A. Adams (Eds.), Aging and work in the 21st century (2nd ed., pp. 191-212). New York, NY: Routledge. https://doi.org/10.4324/9781315167602-9

Field, A. P. (2013). Discovering Statistics using R. New Delhi: Sage Publications.

Gathiira, T. G., Muathe, S. M., \& Kilika, J. M. (2018). Effects of Employees Based Financial Programmes on Retirement Preparedness among Teachers in Kenya. IOSR Journal of Business and Management, 20(2), 61-69.

Gathiira, T. G., Muathe, S. M., \& Kilika, J. M. (2019a). Employee Engagement in Personal Health Programmes and Retirement Preparedness among Public Secondary School Teachers' in Kirinyaga and Murang'a Counties, Kenya. Journal of Business and Management, 21(3), 48-62.

Gathiira, T. G., Muathe, S. M., \& Kilika, J. M. (2019b). Psychosocial Programmes and Employees Retirement Preparedness: Empirical Evidence from the Educational Sector in Kenya. International Journal of Business Administration, 10(2), 82-95. https://doi.org/10.5430/ijba.v10n2p82

Gray, H. (2007). Creating older entrepreneurs: a development dilemma. Development and Learning in Organizations: An International Journal, 21(1), 12-14. https://doi.org/10.1108/14777280710717425

Griffin, B., \& Hesketh, B. (2008). Post-retirement work: The individual determinants of paid and volunteer work. Journal of Occupational and Organizational Psychology, 81, 101-121. https://doi.org/10.1348/096317907X202518

Hershey, D. A., Jacobs-Lawson, J. M., \& Austin, J. T. (2012). Effective Financial Planning for Retirement. The Oxford Handbook of Retirement. https://doi.org/10.1093/oxfordhb/9780199746521.013.0133

Hesketh, B., \& Griffin, B. (2010). Retirement planning survey (Research Report P2010_015). Sydney: Public Sector Workforce. https://doi.org/10.1093/workar/wau004

Hesketh, B., Griffin, B., Dawis, R., \& Bayl-Smith, P. (2014). Extensions to the Dynamic Aspects of the Retirement Transition and Adjustment Framework (RTAF): Adjustment Behaviours, Work Styles, and Identity. Work, Aging and Retirement, Oxford University Press.

Itika, J. S. (2011). Fundamentals of human resource management: Emerging experiences from Africa. African studies center. African Public Administration and Management series, 2.

Jenkins, E. D. A. (2013). The work-to-retirement transition of academic staff: attitudes and experiences. Employee Relations, 35(3), 322-338. https://doi.org/10.1108/01425451311320503 
Kautonen, T., Van Gelderen, M., \& Fink, M. (2013). Robustness of the theory of planned behavior in predicting entrepreneurial intentions and actions. Entrepreneurship Theory and Practice, 39(3), 655-674. https://doi.org/10.1111/etap.12056

Khapova, S. N., Arthur, M. B., Wilderom, C. P., \& Svensson, J. S. (2007). Professional identity as the key to career change intention. Career Development International, 12(7), 584-595. https://doi.org/10.1108/13620430710834378

Kutlu-Koc, V. (2014). The Retirement-Consumption Puzzle and Unretirement. Netspar Discussion Paper 11. Tilburg: The Network for Studies on Pensions, Aging and Retirement. https://doi.org/10.2139/ssrn.2540043

Lambert, N. M., Negash, S., Stillman, C. F., Olmstead, S. B., \& Fincham, F. D. (2012). A love that does not last: Phonography consumption and weakened commitment to one's romantic partner. Journal of Social and Clinical Psychology, 1(4), 410-438. https://doi.org/10.1521/jscp.2012.31.4.410

Lusardi, A., \& Mitchell, O. S. (2011). Financial literacy and retirement planning in the United States. Discussion Paper No. 02/2011-022. https://doi.org/10.3386/w17108

Maestas, N. (2010). Back to work: Expectations and realizations of work after retirement. Journal of Human Resources, 45(3), 718-748. https://doi.org/10.1353/jhr.2010.0011

Mariappanadar, S. (2012). Do retirement anxieties determine bridge employment preference?. A study among pre-retirees in the Australian construction industry. Emerald Group Publishing Limited, 42(2), 176-204. https://doi.org/10.1108/00483481311309375

McVittie, C., \& Goodall, K. (2012). The ever-changing meanings of retirement. American Psychologist, 67(1), 75-76. https://doi.org/10.1037/a0026259

Ministry of Education. (2010). Educational Statistical Booklet 2003-2007. Government Printers, Nairobi, Kenya.

Moffatt, S., \& Heaven, B. (2017). Planning for uncertainty: Narratives on retirement transition experiences. Ageing \& Society, 37, 879-898. https://doi.org/10.1017/S0144686X15001476

Muratore, A. M., \& Earl, J. K. (2015). Improving retirement outcomes: The role of resources, pre-retirement planning and transition characteristics. Ageing \& Society, 35, 2100-2140. https://doi.org/10.1017/S0144686X14000841

NACADA. (2014). Summary Report of Morbidity and Mortality caused by Alcohol Consumption in various parts of the country, Kenya.

Ntalianis, M., \& Wise, V. (2011). The Role of Financial Education in Retirement Planning. Australisian Accounting, Business and Financial Journal, 5(2), 23-37.

Pleau, R. L. (2010). Gender differences in postretirement employment. Research on Aging, 32(3), 267-303. https://doi.org/10.1177/0164027509357706

Pleau, R., \& Shaumann, K. (2013). Trends and correlates of post-retirement employment 1977-2009. Human Relations, 66(1), 117-145. https://doi.org/10.1177/0018726712447003

Potocnik, K., \& Sonnentag, S. (2013). A longitudinal study of wellbeing in older workers and retirees: The role of engaging in different types of activity. Journal of Occupational and Organizational Psychology, 86, 497-521. https://doi.org/10.1111/joop.12003

Principi, A., Smeaton, D., Cahill, K., Barnes, H., \& Socci, M. (2018). What Happens to Retirement Plans, and Does This Affect Retirement Satisfaction?. The International Journal of Aging and Human Development, 90(2) 152-175. https://doi.org/10.1177/0091415018796627

Quick, H., \& Moen, P. (1998). Gender, employment, and retirement quality: A life course approach to the different experiences of men and women. Journal of Occupational Health Psychology, 3(1), 44-64. https://doi.org/10.1037/1076-8998.3.1.44

Sargent, L. D., Lee, M. D., Martin, B., \& Zikic, J. (2012). Reinventing retirement: New pathways, new arrangements, new meanings. Human relations, 66(1), 3-21. https://doi.org/10.1177/0018726712465658

Shultz, K. S., \& Henkens, K. (2010). Introduction to the changing nature of retirement: an international perspective. International Journal of Manpower, 31(3), 265-270. https://doi.org/10.1108/01437721011050567

Shultz, K. S., \& Wang, M. (2007). The influence of specific health conditions on retirement decisions. International Journal of Aging and Human Development, 65, 149-161. https://doi.org/10.2190/AG.65.2.c 
Shultz, K., \& Wang, M. (2011). Psychological perspectives on the changing nature of retirement. American Psychologist, 66(3), 170-179. https://doi.org/10.1037/a0022411

Taylor, P., \& Earl, C. (2016). The Social Construction of Retirement and Evolving Policy Discourse of Working Longer. Journal of Social Policy, 45(2), 251-268. https://doi.org/10.1017/S0047279415000665

Teachers Service Commission. (2014). Teachers' mandatory retirement on attainment of 60 years of age. Circular No.10/2014.

Thuku, P. W., \& Ireri, A. M. (2013). Relationship between Access to Retirement Information and Retirement Preparation among Prospective Retirees in Nyeri County, Kenya. Open Journal of Social Science Research, 1-6. https://doi.org/10.12966/ojssr.04.01.2013

Tomczyk, Ł., \& Klimczuk, A. (2019). Between Successful and Unsuccessful Ageing: Selected Aspects and Contexts. Kraków: Uniwersytet Pedagogiczny w Krakowie. https://doi.org/10.24917/9788395373718

Topa, G., Moriano, J. A., Depolo, M., Alcover, C., \& Morales, J. F. (2009). Antecedents and consequences of retirement planning and decision-making: A meta-analysis and model. Journal of Vocational Behaviour, 75, 38-55. https://doi.org/10.1016/j.jvb.2009.03.002

Valero, E., \& Topa, G. (2014). Brief Retirement Self-Efficacy-11 Scale (BRSE-11): Factorial Structure and Validity. Journal of Career Assessment, 23(4), 1-9. https://doi.org/10.1177/1069072714553567

Van Dalen, H. P., Henkens, K., Henderikse, W., \& Schippers, J. (2010). Do European employers support later retirement?. International Journal of Manpower, 31(3), 360-373. https://doi.org/10.1108/01437721011050620

Van Solinge, H. V., \& Henkens, K. (2008). Adjustment to and satisfaction with retirement: Two of a kind?. Psychology and Aging, 23, 422-434. https://doi.org/10.1037/0882-7974.23.2.422

Vickerstaff, S. (2006). Retirement decisions: who decides?. Journal of Social Policy, 35(3), 455-472. https://doi.org/10.1017/S0047279406009871

Von Bonsdorff, M. E., Shultz, K. S., Leskinen, E., \& Tansky, J. (2009). The choice between retirement and bridge employment: A continuity and life course perspective. International Journal of Aging and Human Development, 69, 79-100. https://doi.org/10.2190/AG.69.2.a

Wang, M., \& Hesketh, B. (2012). Achieving Well-Being in Retirement: Recommendations from 20 Years of Research. Society for Industrial and Organizational Psychology, Inc. SIOP White Paper Series. https://doi.org/10.1037/e520162013-001

Wang, M., \& Shultz, K. S. (2011). Employee retirement: a review and recommendations for future investigation. Journal of Management, 36(1), 172-206. https://doi.org/10.1177/0149206309347957

Wang, M., Adam, G. A., Beehr, T. A., \& Shultz, K. S. (2009). Career issues at the end of one's career: Bridge employment and retirement. In S. G. Baugh, \& S. E. Sullivan (Eds.), Maintaining Focus, Energy, and Options through the Life Span (pp. 135-162). Charlotte, NC: Information Age.

Wang, M., Henkens, K., \& Van Solinge, H. (2011). Retirement Adjustment: A Review of Theoretical and Empirical Advancements. American Psychologist. https://doi.org/10.1037/a0022414

Wang, M., Olson, D. A., \& Shultz, K. S. (2013). Mid and late career issues: An integrative perspective. New York, NY: Routledge. https://doi.org/10.4324/9780203096475

Warner, D. F., Hayward, M. D., \& Hardy, M. A. (2010). The retirement life course in America at the dawn of the twenty-first century. Population Research Policy Review, 29(6), 893-919. https://doi.org/10.1007/s11113-009-9173-2

Weyman, A., Wainwright, D., O’Hara, R., Jones, P., \& Buckingham, A. (2012). Extending working life: Behavior change interventions (DWP Research Report No. 809). Leeds, England: Central Documents Services.

Winston, N. A., \& Barnes, J. (2007). Anticipation of retirement among baby boomers. Journal of Women \& Aging, 19, 137-159. https://doi.org/10.1300/J074v19n03_10

Zaniboni, S., Sarchielli, G., \& Fraccaroli, F. (2010). How are psychosocial factors related to retirement intentions?. International Journal of Manpower, 31(3), 271-285. https://doi.org/10.1108/01437721011050576

Zhan, Y., Wang, M., Liu, S., \& Shultz, K. S. (2009). Bridge employment and retirees' health.

Zikmund, G. W., Babin, B. J., Carr, C. J., \& Griffin, M. (2010). Business research methods (8th ed.). South-Western: Cengage Learning. 